\title{
Quem conta um conto aumenta muito mais que um ponto: narrativa, produção de si e gênero na produção fílmica com crianças pequenas
}

\author{
Rita de Cácia Oenning da Silva*
}

\begin{abstract}
Resumo
Analisando as performances narrativas do conto Chapeuzinho Vermelho de três crianças pequenas ( $2 \mathrm{a} 4$ anos de idade) frente à câmera filmadora, este artigo apresenta $\mathrm{e}$ discute o modo como essas narrativas tanto expressam quanto constituem o mundo e os sujeitos narradores. Variando na forma narrativa, no conteúdo e nos personagens clássicos do conto, essas performances narrativas revelam como as crianças narradoras entendem e dinamizam relaçóes: entre seus pares (atentando especialmente para as relaçôes de gênero - gender); com outros seres (imaginários ou não); e com o próprio gênero narrativo. A análise aponta para como, através dessas narrativas, estão testando possibilidades (de e entre seres, de linguagens, de fórmulas narrativas, de interação e estética). Chama-se a atenção para a capacidade transformativa e criativa presente nas performances narrativas de crianças pequenas e do aspecto filosófico do seu pensamento. Dessa forma, narrando frente à câmera e à plateia, fazem-se sujeitos: produzem a si mesmas e o mundo.
\end{abstract}

Palavras-chave: Primeira Infância. Narrativa. Gênero.

* Doutora em Antropologia Social pela Universidade Federal de Santa Catarina (UFSC). Pesquisadora do MUSA e Brasil Plural. Diretora Executiva da Shine-a-Light. 


\section{Introdução: performances e a filosofia das crianças}

O filósofo político britânico Isaiah Berlin (1973 apud OTTONI, 2002, p. 122), um dos colegas de John Austin, comenta a resposta que esse the deu quando lhe apontou a seguinte questão:

Suponha que uma criança expresse a vontade de encontrar Napoleão na batalha de Austerlitz, e eu digo: Isto não pode acontecer, e a criança responde: por que náo?; e continuo: Porque isto aconteceu no passado, e você náo pode estar viva agora e também há cento e trinta anos atrás e permanecer com a mesma idade; e a criança insistente continua dizendo: Por que não? e eu volto a dizer: Porque isto não faz sentido, como usamos palavras, para dizer que você pode estar em dois lugares ao mesmo tempo ou voltar ao passado, e esta sofisticada criança diz: se é só uma questâo de palavras, entâo não podemos simplesmente alterar nosso uso verbal? Isto me permitiria ver Napoleão na batalha de Austerlitz e também, é claro, estar onde estou agora no lugar e no tempo?

Berlin (1973 apud OTTONI, 2002) perguntou a Austin o que dizer a esta criança? Deveria dizer que ela confundiu os métodos material e formal ao falar? E Austin respondeu: "Não fale assim. Diga para a criança experimentar voltar para o passado. Diga que não há nenhuma lei contra isso. Deixe-a tentar. Deixe-a experimentar, e ver então o que acontece" (BERLIN, 1973 apud OTTONI, 2002, 122).

Comentando essa passagem no livro de Berlin Paulo Ottoni diz que mesmo considerado exageradamente acadêmico, cauteloso e insistir em estar sempre "exageradamente seguro" de suas defesas antes de se expor, John Austin abriu um debate gigantesco sobre as fronteiras entre linguagem e filosofia. Havia, segundo Ottoni, entendido melhor que ninguém o que é a filosofia.

Pelo comentário feito por Austin a Berlin sobre o que se deveria dizer a uma criança, parece que ele entendera também o encanto do modo de pensar das crianças, sua capacidade criativa e produtiva, que, segundo Berlin (1973), assemelha-se ao pensamento filosófico. Trabalhando com crianças desde 1989, realizando uma antropologia da ação e da imaginação, tenho tentado entender como essas se inserem no mundo e como agem criativamente sobre ele através de suas performances cotidianas e extra-cotidianas e sua narrativas.

Desde Jean Briggs, John Blacking (1967), e Margaret Mead, a antropologia tem estudado crianças, enfatizando sua relação com as manifestaçôes artísticas em diferentes contextos ${ }^{1}$. Pesquisas antropológicas recentes sobre crianças, me incluindo entre essas, 
as apresentam como atores sociais e abordam criticamente a fala e a ação dessas, examinando adaptaçóes contextuais, processos de ensino-aprendizagem, sua relação com a religião, uso da linguagem, relação e uso da tecnologia, da mídia e da música, as formas de narrar e expressar o mundo, entre outros ${ }^{2}$. Apresentam insights de como crianças se envolvem e locomovem entre redes de tradiçôes, cosmologias, linguagens e mídias (WIGGINS, 2010) e como as transformam ${ }^{3}$. Tais pesquisas, assim como as realizadas por mim (SILVA, 1998, 2008), salientam a importância de estudar a capacidade criativa das crianças, tomando sua produção como um meio de acessar seu saber e o saber sobre a sociedade em que essas estão inseridas. Embora crianças devam ser entendidas dentro da particularidade de uma determinada cultura, já que inseridas dentro de um modo particular de viver e ver o mundo, é preciso também entender que como sujeitos, propóem e articulam esse mundo, veem e entendem o mundo que lhes cerca e agem sobre ele.

Por outro lado, estudos das manifestaçóes estéticas em antropologia em diferentes contextos têm destacado que essas não são apenas expressóes de um grupo ou sujeito - são também constitutivos desses. Estudos recentes vêm apontando a importância de pensar a interconexão entre diferentes códigos perceptivos (sonoros, visuais, olfativos, gustativos), buscando uma artisticidade que envolve todas as esferas da vida social, especialmente aquelas referentes à formação de identidades, fabricação do corpo e da pessoa (MONTARDO; WILDE, 2011). Pensando nesse duplo aspecto (o expressivo e o constitutivo) das manifestaçôes estéticas, tenho feito o esforço de refletir sobre como as crianças se utilizam de gêneros de performance para se expressarem, transformarem-se e, mais que tudo, para se inventarem como pessoas em diferentes contextos.

Neste artigo, abordo narrativas de três crianças pequenas ( 2 a 4 anos), à luz da teoria desenvolvida por John Austin (1989) sobre atos de fala e performatividade, para pensar a construçáo de gênero que aparece no evento narrado pelas crianças ${ }^{4}$. Utilizo ainda a análise de performance de Richard Baumam (1977, 1989), Charles Briggs (1996) e Esther Jean Langdon (1999), já que estudos de performance permitem que se olhe para os eventos desde diferentes aspectos, considerando a atuação do sujeito, a multissensorialidade, a interação social, enfocando a contextualização do evento pelos participantes e a construção dos sentidos emergentes. Salienta-se por essa escolha analítica o aspecto emergente do evento, a negociação entre os participantes, a dialogicidade e os poderes poéticos e retóricos do evento (LANGDON, 1999). Considero a arte verbal como uma performance, como propôe Richard Bauman (1977), onde os falantes estão constantemente sendo avaliados pela plateia, e onde há constante negociação dos significados. 
A análise das narrativas das crianças pequenas descrita se preocupará em destacar transformaçóes que esses agregam ao conto, à subjetivação dos personagens nele envolvidos e aos aspectos enfatizados na narrativa em si - a performance narrativa. Enfatizo, assim, a qualidade e a importância da narrativa para crianças na primeira infância (GIRARDELLO, 2007). Embora não sejam normalmente vistas como exímios narradores - um erro analítico sob meu ponto de vista - o evento em análise nos mostra que elementos de alta complexidade narrativa estão em destaque. O próprio narrar é tema de debate entre os três narradores.

\section{Crianças pequenas na produção de imagens: um pouco do contexto do evento narrativo}

Estudando crianças em bairros de periferia em Recife notei que bebês e crianças pequenas são exímios mediadores de mundos, estabelecendo desde sua concepção, relaçôes que possibilitam novos status e posiçôes sociais entre pessoas ou grupos de pessoas (SILVA, 2008). A partir desse trabalho, a realização de uma série de projetos audiovisuais com crianças pequenas ( 0 a 6 anos) possibilitaram observar mais de perto como essas atuam no meio em que vivem.

A tecnologia de filmes, meio usado para ampliação do diálogo com essas crianças, pode ser facilitadora de um ambiente de divertimento, estimulando a criatividade. Viabiliza ainda contato com uma tecnologia nem sempre acessível ao mundo dessas crianças, e amplia a possibilidade de adultos acessarem o saber de crianças pequenas, tomando o que dizem como uma expressão da reflexão sobre o mundo. Filmando com crianças pequenas em diferentes contextos, suas experiências com a arte e com a câmera oferecem para mim oportunidades únicas para pensar como elas, normalmente tidas como sujeitos em formação, estão constituindo-se no mundo ao mesmo tempo em que estáo experimentando as regras sociais na (e da) interaçáo com outros agentes. Venho aproveitando essa produção fílmica colaborativa com crianças pequenas para pensar como essas produzem e reinventam conhecimentos já adquiridos, reinterpretando a realidade e a ficção a partir de referências variadas. No caso que vou analisar, a tecnologia fílmica foi um disparador narrativo entre as crianças; além da presença dos seus pares, da minha própria presença e a do outro adulto que me acompanhava, a presença da câmera certamente foi um estimulante para que elas iniciassem suas performances.

O filme que vou abordar neste artigo se trata de "A incrível história da Vovozinha e o Lobo Mau", que faz parte do Projeto "Mediando Mundos", desenvolvido com crianças pequenas da Creche Comunitária Salgueiro, de Sáo 
Gonçalo, $\mathrm{RJ}^{6}$. Usando a dinâmica participativa de construção de filme ficção (câmera partilhada), em conjunto com crianças e os educadores da Creche Salgueiro, estimulamos a auto filmagem entre essas. Pretendia estimular a capacidade imaginativa e narrativa de crianças pequenas para essas pudessem se expressar, brincar com a tecnologia, interagir com a câmera, estando entre pares.

Durante algumas semanas trabalhamos com as crianças filmando suas brincadeiras, interagindo com elas e com as educadoras da creche. Como resultado desse processo foram realizados oito (8) filmes ficção/animação ${ }^{7}$ e dois (2) documentários, que compóem o DVD "Mediando Mundos".

No filme analisado neste artigo, três crianças entre 2 a 4 anos de idade da Creche Comunitária do Salgueiro apresentam a narrativa da história de Chapeuzinho Vermelho, expondo versóes distintas do conto. A gravaçáo do filme se deu quando as crianças do pré-escolar 2 (turma da educadora Catarina de Oliveira, cuja idade das crianças variava entre 3 e 4 anos de idade) brincavam no parquinho na creche. Filmávamos naquele dia atividades no parquinho e quatro crianças acompanhavam constantemente a filmagem, ajudando a guiar a câmera. Quando íamos parar a filmagem, pois era fim do período letivo, Ana Beatriz Lima de Jesus, 4 anos, aproximouse brincando, colocou o olho muito próximo da lente da câmera. Observando sua imagem no ledscreen, que no momento estava virado para ela, disse: "Que olhos grandes você tem...”. E depois, mudando o tom da voz, responde: "Épra ti olhar melhor...". Daí, observando que sua brincadeira despertou interesse por parte dos colegas e dos dois adultos presentes, sentou-se próximo ao muro ao lado da amiga Emilly ( 3 anos), e contou a história de Chapeuzinho Vermelho, que tinha iniciado segundos antes. A primeira performance narrativa é descrita a seguir.

\section{Chapeuzinho Vermelho}

Segurando o microfone próximo à boca, sentada ao lado de Emilly, Ana Beatriz começa a contar sua história usando a fórmula clássica:

Era uma vez... Chapeuzinho Vermelho [display].

Um dia sua mäe disse: "Chapeuzinho Vermelho, vai dar uns doces pra tua vovó”[fala imitando a voz da mãe de Chapeuzinho].

Ela foi [pausa breve].

Um dia, o Lobo falou com ela:

Lobo Mau (LM): "Chapeuzinho Vermelho, me dá um pouquinho desse doce?...".

Chapeuzinho Vermelho (CV): "Não poooode. É pra minha vovó" [Beatriz enfatiza a fala meiga e um pouco manhosa de 




A narrativa da menina é interrompida por sua colega de turma.

\section{O Pica-Pau disfarçado de Vovozinha}

Emilly Ivo da Silva, 3 anos, que estava sentada ao lado de Ana Beatriz e que ameaçara entrar na narrativa da colega, substituindo Chapeuzinho Vermelho e a Vovozinha por Pica-pau, um personagem que também tem cabeça vermelha, emendou rapidamente um trecho do conto, alterando personagens na sua narrativa ${ }^{8}$.

Emilly: Era uma vez um Pica-pau [display]

foi pra casa da Vovozinha [enquadre trocando o personagem central]

e como [pausa pensativa]

[Ana Beatriz aproveita a quebra da narrativa de Emilly e 
interrompe a narrativa; olhando para os colegas presentes, apela para a audiência, pergunta com certa irritação]: "Ela tá me zoando, não tá...?".

[Emelly ri do comentário da colega, demonstrando que seu objetivo de desafiá-la tinha funcionado, e segue]: $E^{\prime}$ que a Vovozinha foi assim: "lá lá lá lá lá... lá lá lá lá lá... [reported speech/ fala ritmada]

e o Lobo Mau foi.

Dai não era a Vovozinha.

Era o Pica-pau que estava se vestindo de Vovozinha.

Ai de tanto "lá lá lá lá lá" [supressão do verbo cantar] jogou a Vovozinha dentro da água.

As duas meninas se levantam rapidamente, com Ana Beatriz reclamando da versão que a Emilly contou. Diz que não era o Pica-Pau o personagem central da história, mas a Chapeuzinho Vermelho, e discutindo saem em direção aos demais colegas da turma que brincavam ao lado. Dai um terceiro narrador que participava atentamente do evento narrativo aproveita e entra em cena.

\section{Vovozinha decide casar-se com o Lobo Mau}

No meio do debate entre as meninas, Carlos Dias, um colega de 4 anos, também da turma das narradoras, assumiu o controle do microfone que estava na mão de Emilly, e, jocosamente, aproveita a discussão das duas colegas e apresenta sua própria versão da história. Ele assume o personagem principal, o Pica-pau, introduzido por Emilly e transforma a história num caleidoscópio de imagens novas, inventadas e narradas com graça.

[Dirigindo-se ao colega de 3 anos que cuidava do som da filmadora, Carlos chama a atenção do público em voz alta, salientando a função fática]: Tá me ouvindo, Allan?

[E segue dando o enquadre]: É... [pausa] Era uma vez [display].

$e ́, e ́$ [repetição, dando tempo para pensar na sequência da história].

Um Pica-pau veioooo. [prolongamento da voz].

Ai três filhos de Pica-pau foi dar docepra Vovozinha.

Ai o Lobo apareceu e disse: - "Como vai Chapeuzinho e seus pequenininhos?" [reported speech, com performance vocal acentuando a fala do Lobo Mau].

Ai ele foi na casa da Vovó, pegou a Vovó e comeu a Vovó e se vestiu de Vovozinha. Ai aqueles Bebezinhos pequenos pegaram e jogaram o Lobo pra trás da cama [pausa].

ai era um elevador.

Umpassageiro falou: - "dois Pica-paus da Vovó". [reportedspeech]. 
Edai eles foram felizes para sempre e a Vovozinha se casou com ele.

$\mathrm{O}$ outro adulto que como eu estava presente na filmagem, pergunta com tom de espantado: Com o Lobo Mau?

Carlos [Rindo de sua própria imaginaçáo e do espanto do ouvinte, dá ênfase a sua resposta prolongando sua fala]: Ahadaaammm.

A história foi filmada e editada e sempre que mostro o filme a um grupo novo, o encanto das três formas de narrar e do final inusitado agrada a plateia, e me estimulou a dar luz a essas performances, analisando tanto forma quando fundo - performance narrativa e o conteúdo narrado -, o que Susan Engel (1995) sugere para análise de narrativas de crianças.

\section{Performance narrativa, performatividade e os diferentes gêneros em ação}

A história da Chapeuzinho Vermelho já foi discutida sob diferentes aspectos. Darnton (1986) refere-se às diversas versóes do conto que surgiram ao longo de muitos séculos, e lembra que essas sofreram diferentes transformações em diferentes tradiçóes culturais. Para o autor, "Longe de expressarem as imutáveis operaçóes do ser interno do homem, sugerem que as próprias mentalidades mudaram” (DARNTON, 1986, p. 26).

No caso acima descrito, podemos presenciar três versôes distintas do conto, numa sequência que ensina muito sobre as mentalidades, sobre a criatividade do narrador e das artimanhas que envolvem o narrar. Ensina ainda sobre o domínio e o embate presente na produção dos gêneros narrativos.

John Austin (1990), em How to do things with words, traduzido para o português como Quando dizer é fazer: palavras e ação, revoluciona a filosofia analítica da linguagem quando propóe que a fala é performativa, ou seja, ela realiza algo. Com a teoria dos atos de fala, o autor faz uma distinção entre enunciados "constatativos" (que constatam um determinado estado de coisas, e podem ser verdadeiros ou falsos) e enunciados "performativos" (que podem produzir um determinado estado de coisas e não são nem verdadeiros nem falsos, mas efetivos ou não efetivos). Para ele, também os enunciados constatativos são atos, que, tal como os performativos, também têm de obedecer a certas condiçóes para serem bem sucedidos ${ }^{9}$.

O conhecido exemplo citado por Austin (1989) é o do casamento. Para que o casamento seja "feliz", como sugere o autor, é preciso que determinadas condiçóes sejam cumpridas: (a) as circunstâncias em que as palavras são proferidas devem ser apropriadas; (b) o falante deve realizar determinadas ações que sejam físicas ou mentais, ou, ainda, o proferimento de algumas palavras adicionais; (c) a pessoa deve ter 
autoridade para executar o ato. Fatores extralinguísticos - as condiçóes da produção e o sujeito - são essenciais na construção da significação dos enunciados ${ }^{10}$.

As três crianças mostram habilidade narrativa e performática. Introduzem suas narrativas de modo parecido e clássico com o display "Era uma vez...". Mostram-se cientes da importância da presença e da avaliação de uma plateia e, de modo diferenciado, apelam para a participação dessa. Usam tons de voz e sons diferenciados para imitar os diferentes personagens apresentados, chamando atenção do público. Introduzem e finalizam suas histórias, mostrando a importância de um ponto clímax na mesma, e, afinal, explicitam o aspecto competitivo das suas narrativas, promovendo um debate entre o conto clássico e a possibilidade inventiva do narrador.

Observando os narradores um a um, vemos que a riqueza da performance narrativa de Ana Beatriz é evidente. Muda de tons de voz quando muda de personagem no conto, usa sons variados para dar ênfase às situaçóes distintas e para dramatizar o evento. Ela é uma narradora, sob o meu ponto de vista, completa, mostrando competência na sua performance (BAUMAN, 1977). No entanto, no jogo narrativo do grupo, outro narrador lhe desafia e inicia, no meio da fala menina, uma nova versão do conto. Emilly, menina de muita energia e mais nova que Ana Beatriz, ao ouvir a história contada pela colega, introduz uma versão completamente distinta. Faz uma modificação da fórmula clássica do conto, introduzindo na sua versão personagens distintos, presente em mídias diferentes. Introduzido o pica-pau na sua história, traz a versão do desenho animado Pica-Pau, onde, no episódio "Chapeuzinho Vermelho de Araque", faz-se a substituição de Chapeuzinho Vermelho pelo Pica-Pau, que tem também cabeça vermelha. Emilly explicita aqui que livros e filmes apresentam também versóes distintas do conto. Além de trazer à tona o acesso a uma mídia diferenciada - a televisiva -, acata a substituição do personagem, usando um índice dele - a cabeça vermelha. Ela introduz ainda cenas da sua experiência cotidiana quando, criativamente, diz que a vovozinha foi jogada na água. Contou-nos dias antes que sua avó fora empurrada por alguém na água quando estava na praia.

Se por um lado Emilly agencia a presença do conto televisivo e quebra a autoridade do conto tradicional (oficial?), Ana Beatriz agencia o livro que sua professora lera na sala de aula. Ela defende sua forma de narrar quando dizendo para os demais colegas, em tom alto, que a versão do conto apresentada por Emilly e Carlos não é verdadeira. Está em jogo aqui a verdade narrativa.

Mas das três versões do conto Chapeuzinho Vermelho descritas acima, a de Carlos foi a que despertou uma grande algazarra entre o público infantil presente, grande parte crianças de 2 a 4 anos de idade. Carlos tornou-se o narrador em destaque sua performance narrativa foi de grande sucesso, encantando o público. Sua forma de 
narrar certamente era muito diferente da apresentada pela primeira narradora, e seguia a fórmula da segunda. Além de incluir novos personagens no seu conto, como o fez Emilly, o menino explicitou a dialogia própria da narrativa, cativando o público. Em primeiro lugar, ele apela para a funçáo fática, mostrando que a presença da câmera tinha importância. Era preciso ter certeza que o colega que segurava a câmera estava filmando dizendo: “- Está me ouvindo, Allan?”. Chama a atenção dos colegas e dos filmadores, pois quer garantir que está sendo filmado, ouvido, observado. Ele quer atenção à sua performance. Suas palavras querem agir também para a câmera. Seguindo a fórmula narrativa desafiadora da colega Emilly, que introduzia antes dele o Pica-Pau no conto, tomou partido no debate entre as meninas. Nos dois parágrafos que finalizam sua narrativa, acata o diálogo entre audiência e narrador, negociando o fim da história. Quando o adulto presente pergunta se a Vovozinha teria se casado era com o Lobo Mau, ele imediatamente concorda, achando graça do desfecho da sua narrativa.

Se Ana Beatriz náo pode acabar seu conto, sendo forçada pela intromissão da colega Emilly a deixar o final de sua história em aberto, Carlos certamente se aproveita da audiência para surpreender a mesma com sua capacidade de narrador. Carlos tinha alcançado o objetivo de todo narrador quando inicia uma história: tinha conquistado sua plateia. Grande parte dos colegas ria do desfecho da sua história e pareciam apreciar a sua capacidade de invenção. Quando Carlos termina sua versão do Chapeuzinho Vermelho, o debate entre os narradores seguiu com as crianças rindo e discutindo (de modo quase inaudível) sobre como cada qual contara a história, e termina para mim como plateia e participante do evento, quando, finalmente, as crianças saíram correndo umas atrás das outras para o outro lado do parquinho, subindo e descendo no escorregador. Claro que para eles o evento continuou ainda por um bom tempo, já que o próprio evento da narraçáo e da filmagem eram temas que eles seguiram debatendo e contando aos demais colegas, sempre promovendo algazarra e estimulando o conflito entre Emilly, Ana Beatriz e Carlos. Com essa prolongação estavam ainda negociando o significado do evento narrativo, cada qual tentando mostrar a verdade do seu narrar. Foi fundamental no evento como um todo a participação de seus pares, que, como plateia, atuavam com seus comentários, olhares e gestos, estimulando as narrativas dos três pequenos narradores, mas, mais que tudo, servindo de estímulo e palco do evento analisado.

Se, por um lado, podemos dar uma ênfase nessa análise no modo como os narradores lidam com a plateia e como abordam o gênero literário usando suas capacidades performáticas, por outro não se pode deixar de levar em conta como essas três (fabulosas) crianças brincam com o conteúdo dos contos. A ênfase à questão de gênero aparece no evento descrito pelo menos de duas formas mais: a primeira, quando 
se referem a relação entre diferentes grupo de seres que têm iguais caracteres essenciais (como entre humanos e lobos, ou pica-paus disfarçados de vovozinha, por exemplo); e a segunda, quando estáo abordando relaçóes de gênero associadas a papéis e posicionamentos de cada um dos personagens - gender - flexáo pela qual se exprime o sexo real ou imaginário dos seres.

Vejamos: na narrativa das crianças a parte do conteúdo que mais surpreende a audiência é o casamento da vovozinha com o lobo mau. Se seguirmos a lógica de Austin (1989), que cita como exemplo de ato performativo um casamento (onde as palavras estão fazendo algo), no evento narrado pelas crianças o casamento entre o Lobo Mau e a Vovozinha parece não ser possível. Fica entáo uma pergunta: ele se realiza ou não? Segundo Carlos, sim, ele se realiza. No entanto, em termos performativos, sugiro, o inusitado do desfecho do conto é o que realiza algo no processo narrativo. O casamento entre duas espécies, misturando gênero humano e animal surpreende, e por isso mesmo viabiliza o novo - produz uma possibilidade extra daquela esperada pelo público presente e pelo senso comum do "quem casa com quem?".

Se a Vovó no conto clássico é atacada ou se assusta com o Lobo e é salva pelo Caçador, na história contada por Carlos ela mesma agencia essa relaçáo e se casa com o Lobo Mau - um animal -, realizando, assim, parentesco entre espécies. Humanos e não humanos estáo sob o mesmo estatuto. Esse desfecho da narrativa de Carlos também confunde a divisão entre bom e mau, tão presente no conto clássico. Vovozinha, frágil e submetida aos desejos e à maldade do Lobo, toma a situação nas mãos e se casa com ele. O bom e mau constituem um casal: acasalam-se. E, nesse instante, onde o conto de Carlos desafia essas regras, ele está se construindo como sujeito instaurando sua própria verdade narrativa.

Aproveitando o debate, a teoria dos atos de fala e os enunciados constatativos e performativos de Austin (1989) e as noções de citacionalidade e reiteração de Derrida (1991), Judith Butler (2003) discute gender (traduzido para o português como gênero) e sexo desenvolvendo a noção de performatividade de gênero: "o gênero mesmo não deve ser meramente concebido como a inscrição cultural de significado num sexo previamente dado (uma concepção juridica) tem de designar também o aparato mesmo de produção mediante o qual os próprios sexos são estabelecidos" (2003, p. 25).

Segundo a autora, o papel do gênero seria produzir a falsa noção de estabilidade, pela repetição de atos, gestos e signos, do âmbito cultural, que reforçariam a construção dos corpos masculinos e femininos, tais como nós os vemos atualmente. Trata-se, portanto, de uma questáo de performatividade. Para Butler (2003), gender (gênero) é um ato intencional, um gesto performativo que produz significados. Sendo performativo, o gênero é constituinte da identidade que supostamente é (2003, p. 48). 
Voltemos às narrativas das crianças: além da farsa do Lobo Mau que se veste de Vovó na clássica história, a troca de personagens na versão da Emilly também apresenta uma possibilidade diferente para os gêneros. Voltemos a sua história: "É que a Vovozinha foi assim: "lá lá lá lá lá... lá lá lá lá lá...[reported speech/ fala ritmada] e o Lobo Mau foi. Dai não era a Vovozinha, era o Pica-pau que estava se vestindo de Vovozinha". Existe nesta parte também uma trans-figuração de gêneros e de espécies. O Pica-pau veste-se de Vovozinha, como no caso do Lobo Mau, e o Lobo Mau tem que lidar com a construção disfarçada (ou seria travestida) de Vovó. Emilly explicita como o gênero é complexo no conto tradicional - o lobo pode se disfarçar de vovozinha, conversar com a Chapeuzinho etc., e colocar em dúvida sua identidade de gênero (é humano, é masculino?). Mas na versão de Emilly é o Pica-Pau quem imita a vovozinha, subvertendo ou confundido o lobo. O Lobo, por sua vez, decide ao invés de comer o Pica-Pau, irritado com a persistente pela cantoria $(L a ́, L a ́, l a ́$, que na narrativa clássica é da Chapeuzinho), decide jogar a vovozinha dentro água.

Claro que sabemos que as crianças não estão redefinindo completamente relações de gênero contando suas versôes do Chapeuzinho Vermelho. Segundo Butler (1993, p. 2), a performatividade deve ser compreendida não como um "ato" "singular ou deliberado, mas, ao invés disso, como a prática reiterativa e citacional pela qual o discurso produz os efeitos que ele nomeia". Ainda para a autora o gênero "é a estilizaçáo repetida do corpo, um conjunto de atos repetidos no interior de uma estrutura reguladora altamente rígida, a qual se cristaliza no tempo para produzir a aparência de uma substância, de uma classe natural de ser" (BUTLER, 2003, p. 59). Portanto, seria necessário muito mais que um conto modificado para estabilizar as relaçóes estabelecidas entre os vários sujeitos que estavam envolvidos naquele evento. No entanto, pode-se ainda pensar o que essas performances estão sugerindo.

Sugiro que os enunciados e as performances das crianças realizam diversas açôes. Seguindo as reflexóes de Austin (1989), de Butler (1993, 1997, 2003) e de Bakhtin (2006) sobre os atos de fala e da performatividade, sugiro que nas performances descritas acima as crianças estão desafiando (e/ou negociando, e/ou ainda zombando dos) diferentes gêneros:

(1) Em primeiro lugar, o gênero narrativo torna-se alvo de embate no fluxo das suas performances. Náo parecia que tinham planejado o evento, mas esse surgiu revelando diferentes modos de perceber a própria narrativa e o que se considera como verdade narrativa, o que implicou numa análise da competência do narrador pela plateia presente. Quando Emily e Carlos propóem uma história tâo diferenciada daquela que se conta tradicionalmente, introduzindo novas cenas ao conto (inclusive cenas da sua vida cotidiana), estâo brincando com as 
convenções e colocando em diálogo e em dúvida o que importa numa narrativa. Parece que para eles a performance do narrador é mais importante que defender a verdade do conto - estão desestabilizando e desafiando os gêneros narrativos valorizados por alguns de seus colegas mais velhos e os professores (a fórmula considerada correta de Chapeuzinho Vermelho);

(2) Também entraram em embate nas suas performances categorias como gênero e espécies, desafiando binarismos narrativos como verdades/ficção e desfechos simplificados entre os personagens (se é que desfechos simplificados existam em contos). Nesse sentido, essas narrativas mostram mentalidades abertas que (ainda) se permitem criar novas fórmulas. As versóes das duas últimas crianças mostram como as relaçóes binárias masculino/feminino, humano/animal, natureza/cultura, e porque não dizer, seguindo Butler (2003) , sexo/gênero, não estão dadas de modo permanente naquele universo narrativo. São categorias em jogo no evento narrativo, nas suas performances. De algum modo o que está em jogo é o que é a nossa verdade narrativa sobre nós mesmos. Quem somos para nós e quem podemos ser para os outros. Embora, como disse, sabemos que a narrativa das crianças não transforma totalmente o jogo binário insistente sobre o gender (por exemplo), penso que é interessante notar como essas estão criando outras possibilidades performativas imaginárias, produzindo e buscando referências outras enquanto narram e inventam histórias. A necessidade de repetição que se observa tão frequentemente na vida de crianças pequenas, sempre repetindo os mesmos jogos e ouvindo as mesmas histórias, faz parte dessa necessidade da produção de referências, sejam elas de gênero, de verdades, de saberes.

Para Bakhtin (2006, p. 114), não é a atividade mental que organiza a expressão, mas, ao contrário, é "a expressão que organiza a atividade mental", que a modela e determina sua orientação. Já nos estudos de performance, salienta-se que num evento narrativo o estético está em relevo e os significados são negociados e atualizados no momento de sua produção (LANGDON, 1999). Nesse sentido, o evento narrativo analisado parece um jogo entre os narradores, onde esses expressam concepçóes e uma estética próprias sobre o mundo. Para Briggs (1996, p. 4), as narrativas podem apresentar modelos de ação social, mas afirma que "O status da produção narrativa e a da recepção como atividade socialmente situada exerce um papel crucial na constituiçấo - e não somente na reflexão - da vida cotidiana. [...]”. Assim, o evento narrativo constitui a vida social e não somente reflete a mesma. Constituindo a vida social, é também um espaço de subjetivação e construção de si, pois os sujeitos em relaçáo estáo negociando sua própria imagem frente aos demais - sua identidade de 
narrador também está em relevo. Portanto, o evento analisado constitui-se num espaço onde as crianças estão negociando seus significados e produzindo a si mesmas como atores sociais.

Para Austin (1989), todo dizer realiza algo. Assim, salientou que o fazer das falas e do evento acima descrito se dá náo na linguagem e pela linguagem. A atuação de cada uma das crianças realiza algo e a performance como um todo - o evento em si - tem ainda mais uma ação: a do embate entre os pares e com a convençóes as quais estáo sendo apresentadas.

Desse modo, além de se expressarem, as crianças pequenas, cuja narrativa analiso nesse texto, estâo experimentando (e desafiando) regras (convençôes) de relaçôes, de invençôes e da própria linguagem. Desafiam o meio: a linguagem (a comunicação - e não somente a verbal, mas a gestual etc.). Expressando, permitem que se teste as regras sociais - e que se experimente as convençôes -, mas também permite testar quais novas regras e coisas podem ser inventadas. A linguagem mesma não está excluída dessa experimentação. O grau de complexidade com que crianças fazem isso não difere do adulto - o que talvez seja distinto é o fato de (por necessidade ou por criatividade mesmo, ou seja, pelo gosto do jogo) se experimentarem com muito mais frequência. E, por isso, a repetição, uma qualidade tão observada na vida cotidiana das crianças pequenas - elas querem uma vez mais e outra mais, ver, experimentar, jogar, ouvir outra e outra vez. Fazem inúmeras tentativas para descobrirem onde e quando convençôes e mudanças (simbolização diferenciante) (WAGNER, 2010) são possíveis.

O evento abordado neste artigo, portanto, expressa e constrói a própria subjetivaçáo do narrador e sua capacidade de fazer interagir mundos em diferentes níveis, contextualizando e recontextualizando histórias, incluindo a sua própria. Desse modo, friso que a experiência narrativa é um aspecto fundamental para a expressão e constituição de sujeitos em qualquer fase da vida. Constroem através do ato de narrar não somente histórias inusitadas e cheias de criatividade, com desfechos também inusitados e abertos; constroem relaçóes entre os seus e seus outros - agregam-se, desagregam-se, concordam e discordam, jogam com a convenção, jogam com a invenção. $\mathrm{O}$ evento narrativo é um momento onde reatualizam o jogo vivido tanto na literatura e na mídia quanto no fluxo do momento. Essas interaçôes são interaçôes que a matéria humana (no sentido ampliado do perspectivismo) permite, que a imaginação permite.

Consideradas com certa frequência como "incompletas" ou "em formação", ou mais "próximas da natureza", com suas performances narrativas surpreendem quase sempre com o poder da sua imaginaçấo. Benjamin (1987, p. 229), no texto Desempacotando minha biblioteca, diz que as "crianças decretam a renovação da 
existência por meio de uma prática centuplicada e jamais complicada”. Para elas, toda ação é um "processo de renovaçáo". Renovemos-nos com elas e por elas. Como as crianças, em cada conto nos permitamos aumentar muito mais que um ponto. A imaginação não tem limites. Ao menos ela.

\section{Notas}

${ }^{1}$ Ver: Minks (2006), Emberly (2003), Silva (2008), Satiko (2005), Gaunt (1997), Campbell e Scott-Kassner (1995), Wiggins (2010), entre outros.

${ }^{2}$ As crianças aparecem em trabalhos clássicos e pioneiros, como os de Bronislau Malinowski, Margaret Mead, Jean Briggs. Para uma análise da literatura das ciências sociais sobre crianças no meio urbano até 1988, ver Alvin e Valladares (1988). Para uma análise da literatura internacional sobre crianças e antropologia, ver Levine (2007). Sobre crianças indígenas ver Silva, Macedo e Nunes (2002) e Tassinari (2007).

${ }^{3}$ No Brasil cito alguns trabalhos: Cohn (2000), Silva (2008), Leckzniesk (2007), Alvares (2005), Tassinari (2007), entre outros.

${ }^{4}$ No artigo Performance Narrativa, literatura oral e subjetivação entre crianças pequenas: $o$ caso do lobo mau (que casou) com a vovozinha (SILVA, 2014), abordo o mesmo evento narrativo que analiso aqui. Em 2014 analisei a capacidade de crianças pequenas em subjetivar os personagens do evento narrado. Discuto os seguintes pontos: (1) como eventos narrados e eventos narrativos se relacionam para seus narradores e o público presente; (2) como o evento narrativo expressa a própria subjetivação do narrador e sua capacidade de fazer interagir mundos em diferentes níveis, contextualizando e recontextualizando histórias, incluindo a sua própria; e (3) como a experiência narrativa é um aspecto fundamental para a expressão e constituição de sujeitos em qualquer fase da vida.

${ }^{5}$ Disponível em: <http://www.youtube.com/watch?v=dWEUdlO4iPQ>. Acesso em $10 / 11 / 2015$.

${ }^{6}$ O projeto "Transiçôes" foi elaborado e desenvolvido em parceria entre ArtCreche e Shine a Light e financiado pela Bernard Van Leer Foundation.

${ }^{7} \mathrm{O}$ projeto foi desenvolvido por mim e pelo diretor executivo de Shine a Light, Kurt Shaw, sendo eu a editora e ele o animador dos filmes.

${ }^{8}$ Um dos episódios da animação Pica-Pau faz uma substituição de Chapeuzinho Vermelho pelo personagem. Ver "Pica-Pau: Chapeuzinho Vermelho de Araque", d i s p o n í v e 1 e m : <http://www.youtube.com/watch?v=H8apAnzNkvs\&feature=related $>$. Acessado em 20/10/2015.

${ }^{9}$ Austin (1989) critica as abordagens tradicionais que enfatizavam a função referencial da linguagem e chama a atenção para os aspectos ilocucionários dos símbolos, que em determinadas performance fazem coisas com palavras. Segundo o autor, toda 
enunciação é um ato de fala (speech acts), que, por sua vez, consiste em três aspectos: Atos Locucionários (que cuida da dimensão linguística), Atos Ilocucionários (onde está contido o núcleo do ato de fala, a força ilocucionária) e os Atos Perlocucionários (trata das consequências alcançadas pelo ato).

${ }^{10}$ Muitas dessas ideias estão presentes em Wittgenstein (1973), na obra Investigaçóes Filosóficas.

\section{REFERÊNCIAS}

ALVARES, Myriam Martins. Kitoko Maxakali: a criança indígena e os processos de formação, aprendizado e escolarização. Anthropológicas, Pernambuco, v. 15, p. 4978, 2005.

ALVIN, Rosilene; VALLADARES, Lícia do Prado. Infância e sociedade no Brasil: uma análise da literatura. Boletim Informativo e Bibliográfico de Ciências Sociais, n. 26, jul./dez. 1988.

AUSTIN, John L. Outras Mentes. Tradução de Marcelo Guimarães da Silva Lima. 4. ed. São Paulo: Nova Cultural, 1989. (Coleção Os Pensadores).

AUSTIN, John L. Quando dizer é fazer: palavras e ação. Tradução de Danilo Marcondes de Souza Filho. Porto Alegre: Artes Médicas, 1990.

BAKHTIN, Mikhail. Estética da Criação Verbal. São Paulo: Martins Fontes, 2006.

BAUMAN, Richard. Verbal art as performance. Rowley: Newbury House Publishers, 1977.

BENJAMIN, Walter. O Narrador: considerações sobre a obra de Nikolai Leskov. In: BENJAMIN, Walter. Magia e técnica, arte e politica: ensaios sobre literatura e história da cultura. São Paulo: Brasiliense, 1987. p. 197-221. (Obras escolhidas, v. $1)$.

BLACKING, John. Venda children's songs: a study in ethnomusicological analysis. Johanesburg: Witwatersrand University Press, 1967.

BRIGGS, Charles. The politics of discursive authority in Research on the "Invention of Tradition". Cultural Anthropology, Houston, v. 11, n. 4, 1996.

BUTLER, Judith P. Bodies that matter: on the discursive limits of "sex". New York: Routledge, 1993.

BUTLER, Judith P. Excitable speech: a politics of the performative. New York: Routledge, 1997. 
BUTLER, Judith P. Problemas de gênero: feminismo e subversão da identidade. Tradução de Renato Aguiar. Rio de Janeiro: Civilização Brasileira, 2003.

CAMPBELL, Patricia; SCOTT-KASSNER, Carol. Music in childhood: from Preschool through the Elementary Grades. New York: Schirmer Books, 1995.

CARSTEN, Janet. "Children in Between: Fostering and the Process of Kinship on Pulau Langkawi, Malaysia”. Man 26: 425-43. k: Oxford, 1991.

COHN, Clarice. A criança indígena: a concepção Xikrin de infância e aprendizado. 2000. Dissertação (Mestrado em Antropologia) - Universidade de São Paulo, São Paulo, 2000.

DARNTON, Robert. O grande massacre de gatos e outros episódios da história cultural francesa. Rio de Janeiro: Graal, 1986.

DERRIDA, Jacques. Assinatura acontecimento contexto. In: DERRIDA, Jacques. Limited Inc. Tradução de Constança Marcondes Cesar. Campinas, SP: Papirus, 1991, p. 11-37.

EMBERLY, Andrea. Exploring Children's Musical Culture in Ethnomusicology. Finland: UNESCO, 2003.

ENGEL, Susan. The stories children tell: making sense of the narrativas of Childhood. Nova York: Freman and Company, 1995.

GAUNT, Kyra Danielle. The games black girls play: music body and "soul". Michigan: Ann Arbour, 1997.

GIRARDELLO, Gilka. Voz, presença e imaginação: a narração de histórias e as crianças pequenas. In: FRITZEN, Celdon; CABRAL, Gladir (Org.). Infância: imaginação e educação em debate. Campinas, SP: Papirus, 2007. p. 39- 57. (Coleção Ágere).

LANGDON, Ester Jean. A fixação da narrativa: do mito para a poética da literatura oral. Horizontes Antropológicos, Porto Alegre, RS, ano 5, n. 12, p. 13-36, dez. 1999. LEVINE, Robert A. Ethnographic studies of childhood: a historical overview. American Anthropologist, v. 109, n. 2, p. 247-260, 2007.

MINKS, Amanda. Interculturality in play and performance: Miskitu children's expressive practices on the Caribbean coast of Nicaragua. 2006. Tese (Doutorado em Antropologia Social) - Universidade de Columbia, Nova Iorque, 2006. 
MONTARDO, Deise L.; WILDE, Guillermo. Introducción: objetos, lenguajes y estéticas sonoro-visuales amerindios. TRANS: Revista Transcultural de Música/Transcultural Music, n. 15, 2011.

OTTONI, Paulo. John Langshaw Austin e a Visão Performativa da Linguagem. DELTA, São Paulo, v.18, n. 1, p. 117-143, 2002.

SATIKO, Rose. "Etnografia da performance musical - identidade, alteridade e transformação." Horizontes Antropológicos. UFRGS. IFCH. Ano 11, n. 24. Porto Alegre: PPGAS, 2005.

SILVA, Aracy Lopes; NUNES, Ângela; MACEDO, Ana Vera (Org.). Crianças indígenas: ensaios antropológicos. São Paulo: Global, 2002.

SILVA, Rita de Cácia Oenning. A Porta entreaberta: prática e representaçóes em torno das relaçóes entre casa e rua junto a crianças e adolescentes de camadas populares de Fpolis. 1998. Dissertação (Mestrado em Antropologia Social) Universidade Federal de Santa Catarina, Florianópolis, SC, 1998.

SILVA, Rita de Cácia Oenning. Performance narrativa, literatura oral e subjetivação entre crianças pequenas: o caso do lobo mau que casou com a vovozinha. In: MONTARDO, Deise Lucy; DOMINGUEZ, Maria Eugênia (Org.). Arte e sociabilidades em perspectiva antropológica. Florianópolis: Editora da UFSC, 2014. p. 207-229.

SILVA, Rita de Cácia Oenning. Superar no movimento: etnografia de performances de Pirráias em Recife e mais além. 2008. Tese (Doutorado em Antropologia Social) - Universidade Federal de Santa Catarina, Florianópolis, SC, 2008.

TASSINARI, Antonella. Concepçóes indígenas de infância no Brasil. Tellus, Campo Grande, v. 7, n. 13, p. 11-25, maio/out. 2007.

TOREN, Christina. "Children's perception of gender and hierarchy in Fiji”. In: JAHODA, Gustav and LEWIS, I. M. (Ed). Acquiring Culture: Cross-Cultural Studies in Children Development. London: Cross Helm, 1988.

WAGNER, Roy. A invenção da Cultura. São Paulo: Cosac Naify, 2010.

WIGGINS, Trevor. Changing sound ecologies: children in Northern Ghana. Society for Ethnomusicology, Los Angeles, 2010.

WITTGENSTEIN, Ludwig. Philosophical Investigations. London: Pearson, 1973. 


\section{More than just telling tales: narrative, self-production and gender in film production with small children}

\begin{abstract}
Through an analysis of the narrative performances of the tale "Little Red Riding Hood" by three small children (2 to 4 years old) in front of the video camera, the article presents and discusses the way these narratives both express and produce the world and the narrator individuals themselves. As they vary the narrative form, the plot, and the characters, these children's performances reveal how they understand and catalyze relations with their peers (especially subverting gender relations), with other beings (imaginary or not), and with narrative genre. The analysis indicates how, through these narratives, they test the possibilities of beings, of interaction, and of language, opening a range of possibilities for an aesthetic of self. Based on an extensive background of film production with children, we point out the philosophical aspects of this production, showing how the performative and creative capacity of children opens a space where they represent themselves. Narrating for the camera or for an audience, these children turn themselves into social subjects, thus producing themselves and the world.
\end{abstract}

Keywords: First Childhood. Narrative. Gender.

El cuento va más allá de lo
contado: la narrativa, la
producción de sí mismo y el
género en la producción
cinematográfica con niños
pequeños

\section{Resumen}

Analizando de las narrativas del cuento Caperucita Roja contadas por tres niños pequeños (2-4 años) en frente de la filmadora, este artículo presenta y discute cómo estas narrativas expresan tanto el mundo como también constituyen a sus narradores como sujetos. Estas actuaciones narrativas revelan cómo los pequeńos narradores entienden y crean relaciones: entre sus pares (con especial atención a las relaciones de género); con otros seres (de ficción o no); y con su propio género narrativo. Los análisis apuntan a las posibilidades de cómo, a través de estos relatos, están probando posibilidades (entre los seres, las lenguas, las fórmulas narrativas, la interacción y la estética). Llama la atención sobre la capacidad transformadora y creativa de estas interpretaciones narrativas de los niños pequeńos y el aspecto filosófico de su pensamiento. Por lo tanto, haciendo la narración delante de la cámara y del público, se convierten en sujetos: ellos mismos se producen y también así producen el mundo.

Palabras claves: Primera Infancia. Narrativa. Género. 


\section{Rita de Cácia Oenning da Silva}

E-mail: oenningdasilva@gmail.com

Recebido em: 10/12/2014

Aprovado em: 9/6/2015 